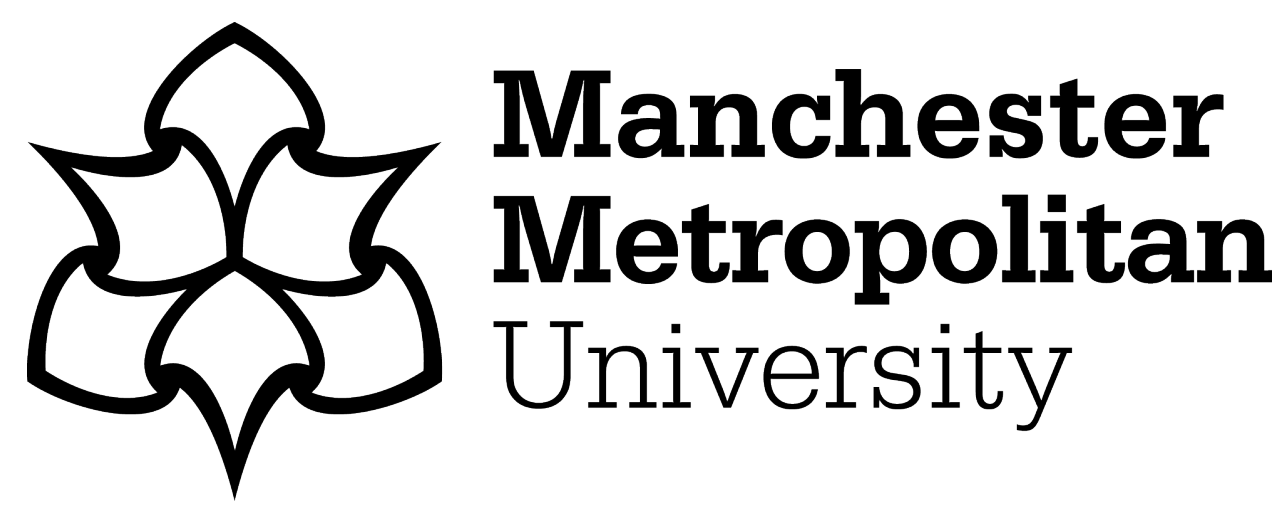

Massey, Simon ORCID logoORCID: https://orcid.org/0000-0003-0550-0613 (2020) Book Review: Education for Democratic Intercultural Citizenship. Citizenship Teaching \& Learning, 15 (3). pp. 391-392. ISSN 1751-1917

Downloaded from: https://e-space.mmu.ac.uk/626994/

Version: Accepted Version

Publisher: Intellect

DOI: https://doi.org/10.1386/ctl_00042_5

Please cite the published version 


\title{
Reviews
}

Simon Massey

Review

\section{Education for Democratic Intercultural Citizenship, Wiel Veugelers (2019)}

\author{
Leiden and Boston: Brill, 194 pp.,
}

ISBN 978-9-00441-194-4, €45.00/ \$54.00

Reviewed by Simon Massey (ORCID ID: https://orcid.org/0000-0003-0550-0613)

Contact: Manchester Metropolitan University, 343 Geoffrey Manton Building, 4 Rosamond Street West, Manchester M15 6LL, UK.

E-mail: S.Masseymmu.ac.uk

Education for Democratic Intercultural Citizenship $+(\mathrm{EDIC}+)$ is the result of a strategic partnership in Education for Democratic Citizenship funded by an Erasmus + programme. The partnerships aimed to respond to some concerns about young people's disengagement with European democracy. Erasmus provided an opportunity for universities to work together in developing EDIC that not only teaches students to become intercultural citizens, but also encourages them to. The book offers a well-informed and realistic suggestion to providing university students an opportunity to learn intercultural values by working alongside students from other cultures, gain experience in contributing to democracy through their learning and (Veugelers argues) provide more opportunities for future European Economic Growth.

Chapters 2-8 consider each partaking University's module, along with their theoretical framework, curriculum guidelines and participating students' experiences. With each University providing their own field of expertise, the chapters complement one another in highlighting, for various reasons, why EDIC + could serve as a contributor to the conservation of European Democracy. Kesidou's Chapter 8 (or module) highlights this, 
discussing children refugees' democratic right to an education that has not stood during a time of alarming increases in nationalism and racism.

Reading this book created a desire for a critical discussion on the pedagogic approach of EDIC+ practitioners across the partaking universities. Whilst Veugelers' Chapter 11 provides an informative description of the five methodological elements for all modules, a separate debate would arguably demonstrate further how this programme encourages Education for Democratic Intercultural Citizenship in the authentic learning processes. The very values of the book and EDIC+'s intentions, such as inclusivity, would arguably be most met through student-centred learning, as students communicate with one another and learn of their differences.

A pedagogic similarity noticed, was the use of group work to assess students' understanding in a range of tasks across a number of the participating institutions. This reflected the overall aims of EDIC + by improving student confidence and motivation, whilst gaining skills such as communication and teamwork (Salas et al. 2009). Whilst these methods are known for eliciting higher student satisfaction (Burke 2011), improving such skills would also arguably contribute to the future European Economic Growth Veugelers refers to in this book.

In conclusion, Education for Democratic Intercultural Citizenship is a highly recommended read. Bhatti sums up EDIC+ in Chapter 10; it is one thing to explore the meaning of democracy and another to teach future practitioners to consider policy and facilitate their participation in research, whilst EDIC+ aims to do both. The safe environment created by practitioners can provide an opportunity for students to feel comfortable exploring democracy by engaging in the democratic processes when learning. Reading this book shows just how much impact practitioners can have in their work to tackle present-day challenges. If that is not enough, simply reading the inspiring comments from students who participated in 
this programme provides evidence of why a programme such as EDIC + is needed more than ever.

\section{References}

Burke, A. (2011), 'Group work: How to use groups effectively', The Journal of Effective Teaching, 11:2, pp. 87-95.

Salas, E., Rose, M. Pavlas D., Jensen, R. Fu, D., Ramachandran, S., Hinkelman, E. and Lampton, D. (2009), Understanding Demonstration-Based Training: A Definition, Conceptual Framework, and Some Initial Guidelines, Arlington, VA, United States Army Research Institute for the Behavioral and Social Sciences. 